Case Report

\title{
Xeroderma Pigmentosum with Severe Neurological Manifestations/De Sanctis-Cacchione Syndrome and a Novel XPC Mutation
}

\author{
Esteban Uribe-Bojanini, ${ }^{1}$ Sara Hernandez-Quiceno, ${ }^{2}$ and Alicia María Cock-Rada ${ }^{3}$ \\ ${ }^{1}$ Departamento de Dermatología, Universidad CES, Calle 10 A 22-04, Medellín, Colombia \\ ${ }^{2}$ Departamento de Endocrinología Pediátrica, Universidad de Antioquia, Carrera 51D 62-29, Medellín, Colombia \\ ${ }^{3}$ Unidad de Genetica Médica, Facultad de Medicina, Universidad de Antioquia, Carrera 51D 62-29, Medellín, Colombia
}

Correspondence should be addressed to Alicia María Cock-Rada; alicia@oncogenetica.co

Received 21 July 2016; Revised 20 December 2016; Accepted 11 January 2017; Published 1 February 2017

Academic Editor: André Mégarbané

Copyright ( 2017 Esteban Uribe-Bojanini et al. This is an open access article distributed under the Creative Commons Attribution License, which permits unrestricted use, distribution, and reproduction in any medium, provided the original work is properly cited.

\begin{abstract}
Several genetic disorders caused by defective nucleotide excision repair that affect the skin and the nervous system have been described, including Xeroderma Pigmentosum (XP), De Sanctis-Cacchione syndrome (DSC), Cockayne syndrome, and Trichothiodystrophy. Cutaneous photosensitivity with an increased risk of skin malignancy is a common feature of these disorders, but clinical manifestations commonly overlap these syndromes. Several genes have been found to be altered in these pathologies, but we lack more genotype-phenotype correlations in order to make an accurate diagnosis. Very few cases of DSC syndrome have been reported in the literature. We present a case of a 12-year-old Colombian male, with multiple skin lesions in sun-exposed areas from the age of 3 months and a history of 15 skin cancers. He also displayed severe neurologic abnormalities (intellectual disability, ataxia, altered speech, and hyperreflexia), short stature, and microcephaly, which are features associated with DSC. Genetic testing revealed a novel germline mutation in the XP-C gene (c.547A>T). This is the first case of an XP-C mutation causing De SanctisCacchione syndrome. Multigene panel testing is becoming more widely available and accessible in the clinical setting and will help rapidly unveil the molecular etiology of these rare genetic disorders.
\end{abstract}

\section{Introduction}

Xeroderma Pigmentosum (XP) is a rare autosomal recessive disorder, first described by Hebra and Kaposi in 1874, which is caused by a defective nucleotide excision repair (NER) system, which produces mainly skin, ocular, and neurologic alterations $[1,2]$. This abnormality in DNA repair can lead to XP, De Sanctis-Cacchione syndrome (DSC), Cockayne syndrome (CS), XP/CS complex, and Trichothiodystrophy or overlapping manifestations [3]. XP has been diagnosed worldwide and affects both genders equally. It is rare in Europe and North America with an incidence of 1 in 250.000$1.000 .000[4,5]$ but is more frequent in areas with higher levels of consanguinity, like Japan (incidence of 1 in 20,000) Northern Africa (1 in 10,000-30,000) India, and the Middle East $[6,7]$.
$\mathrm{XP}$ is a genetically heterogeneous disease, which can be caused by pathogenic mutations in several genes involved in the NER pathway including the seven complementation groups XP-A to XP-G, and XP variant that is caused by deficient translesion synthesis. NER is responsible for repairing ultraviolet-induced photoproducts inside DNA and if a mutation is present in any of the components of the pathway, then the entire pathway fails to function normally (Figure 1) [8-10].

XP patients can be categorized into the different complementation groups, according to the mutated gene. The XPC group is the most common in the United States and Europe and is found in $43 \%$ of XP patients [11, 12].

Clinical characteristics vary depending on the complementation group, the nature of the mutation, and sun exposure, as well as other unknown factors. Some are common to 


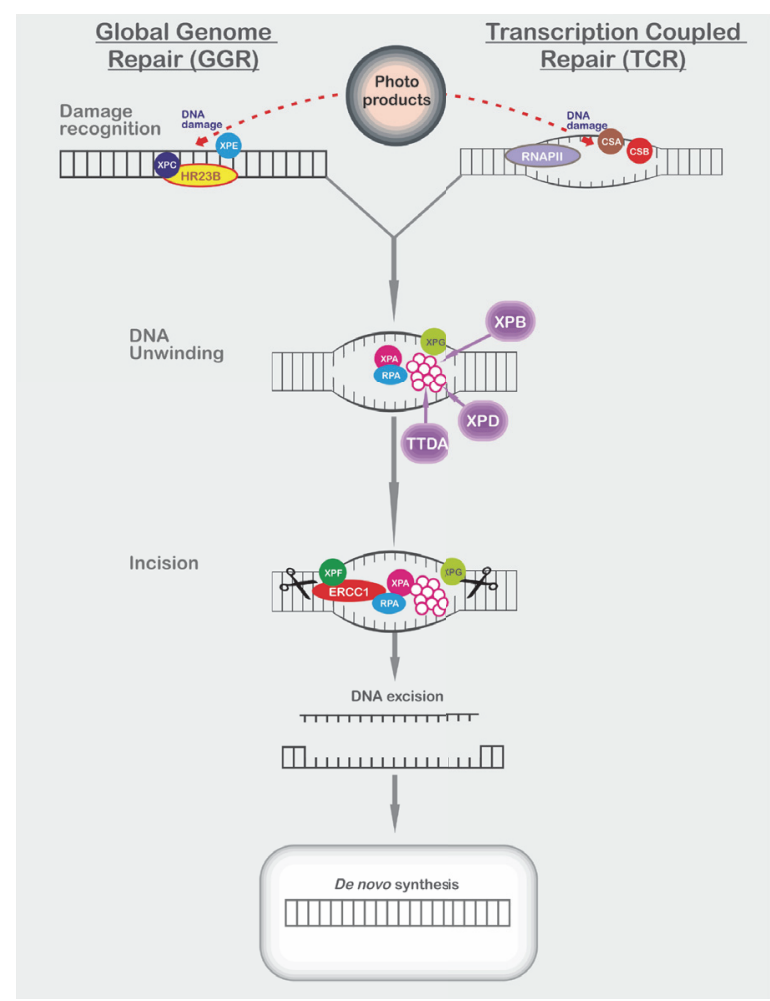

FIGURE 1: Nucleotide excision repair (NER) pathway. Transcription coupled repair (TCR) removes DNA damage from actively transcribed genes and global genome repair (GGR) from the rest of the genome [13]. TCR starts when RNA polymerase stops at the damaged DNA, which acts as a signal for CSA and CSB binding. In GGR, the XPE protein and the XPC-HR23B complex recognize the DNA damage. Upon initial recognition of the DNA lesion, both pathways converge. The XP-B and XP-D DNA helicases unwind the region surrounding the damaged site, along with the XP-A, XP-G, and replication protein A (RPA) [14]. The XPF-ERCC1 nuclease complex and XP-G endonuclease excise the damaged DNA. The resulting gap is replaced by de novo DNA synthesis.

all XP groups; approximately $50 \%$ of XP patients have acute sunburn reaction to minimal sun exposure. All patients have numerous lentigines (freckle-like hyperpigmented macules) on UV-exposed skin [15]. Symptoms usually start between 1 and 2 years of age. Sun exposure causes the skin to become dry with an increase in pigmentation and multiple premalignant actinic keratoses may develop at early ages. XP patients have a 10,000-fold increase in the risk of developing skin basal cell carcinoma and squamous cell carcinoma and a 2,000-fold increased risk of melanoma [16-18]. The median age of non-melanoma skin cancer in XP is 8 years, which is approximately 50 years earlier compared to healthy adults in the United States [2]. XP is also associated with a 20-50fold increase in risk of internal malignancies, such as oral cavity, breast, uterine, brain, renal, gastric, testicular, and lung tumors and leukemia [19-21]. Ocular symptoms are common but primarily affect the anterior UV-exposed area, causing photophobia, conjunctival injection, and reduction in tears. Sun exposure leads to keratitis and corneal opacities and might cause ocular squamous cell carcinoma or melanoma [22]. Approximately 30\% of XP patients present neurologic alterations, which may appear early in infancy or later in the second or third decade of life. They range from mild to severe, with intellectual disability, deafness, spasticity, and seizures [23]. The most severe form of neurologic alterations is known as De Sanctis-Cacchione syndrome: including classical XP manifestations plus hyporeflexia or areflexia, microcephaly, low IQ, progressive mental deterioration, athetosis, ataxia, spasticity, dwarfism, and hypogonadism [24, 25]. Shortening of the Achilles tendon may lead to quadriparesis [3]. Autopsies of XP patients have revealed loss of neurons mainly in the cerebellum and cerebrum. Neurologic alterations have been mainly observed in the group XP-A, XP$\mathrm{B}, \mathrm{XP}-\mathrm{D}$, or XP-G $[12,26]$. Cockayne syndrome (CS) and Trichothiodystrophy (TTD) are disorders that have multisystem affection, with a wide range of symptoms and severity (Table 1) [27]. Patients with CS have a typical face phenotype (microcephaly, wizened face, deep-set eyes, mandible prognathism, hypoplastic teeth, and malformed ears) and develop dwarfism, hypogonadism, and neurological abnormalities such as progressive impairment of vision, hearing and speech, behavioral changes, intellectual disability, and problems with gait, leading to severe disability $[3,5]$. TTD patients present hair and nails with sulphur deficiency, ichthyosis, and neurological affection [28]. Some reports have shown a combined DNA repair disorder, resulting in the XP/CS complex. This combination has been found in the complementation groups XP-B, XP-D, and XP-G, and only about 12 patients have been reported with XP/CS [29].

Although XP can be suspected by clinical features such as extreme UV sensibility in exposed areas and the appearance of numerous lentigines or skin cancer at early ages, molecular 


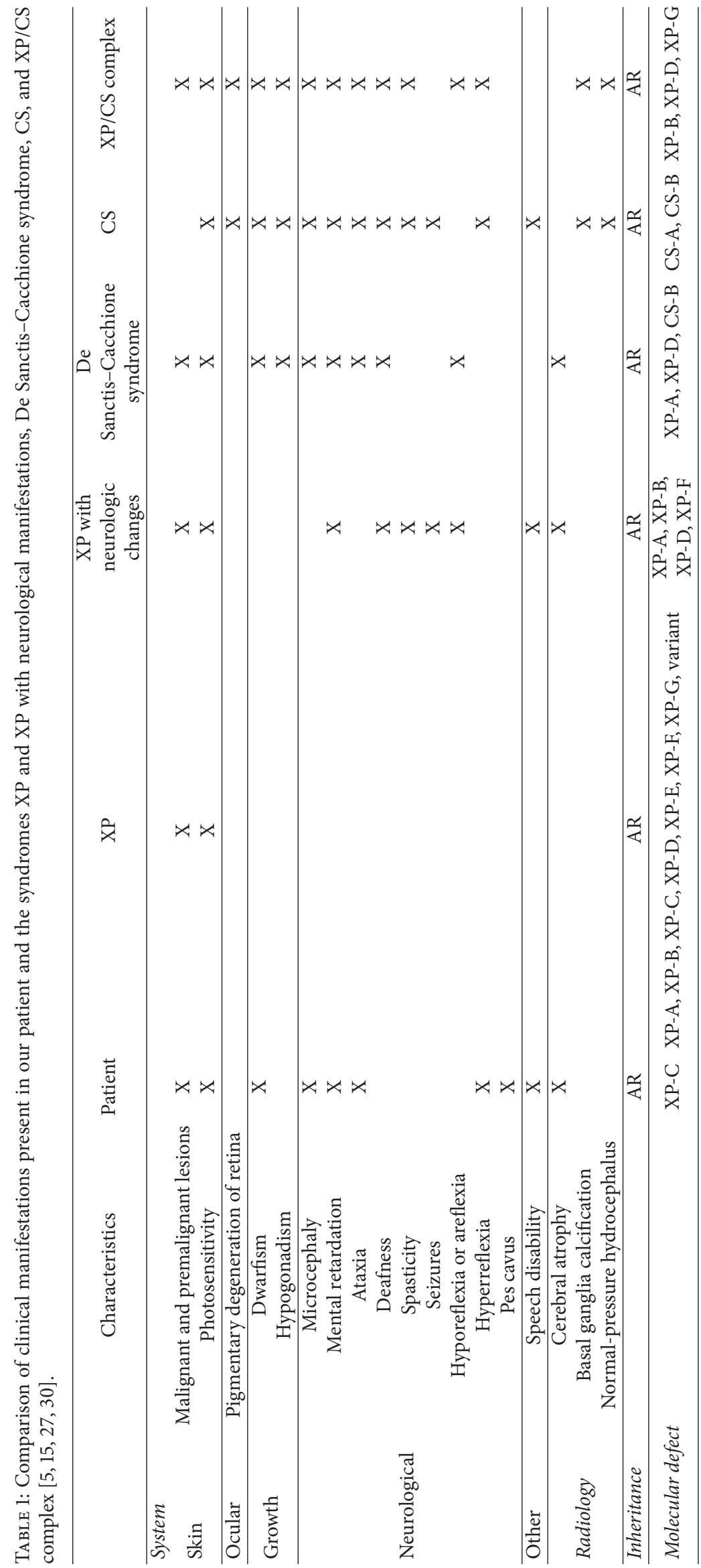


genetic testing is recommended for confirmation of the patient's mutation and complementation group characterization. This is important for genetic counseling, antenatal diagnosis, discussion of etiology, probability of occurrence in future generations, and the increased likelihood of occurrence in communities with high consanguinity.

XP has no cure, but skin complications can be controlled with adequate protection and prevention (sunblock, lip balm, covering clothing, UV-absorbing glasses, or even a facemask) [15]. Indoor environments should have UV film protection on windows, and fluorescent or halogen lights must be avoided. Premalignant lesions such as actinic keratosis should be treated with liquid nitrogen, topical imiquimod, or 5-fluorouracil $[31,32]$. Oral isotretinoin has been effective in preventing the appearance of new neoplasms [33]. Topical DenV T4 endonuclease, a bacterial DNA repair enzyme, has been shown to reduce the appearance of new actinic keratoses in XP patients [34]. A routine evaluation by an ophthalmologist and a skin physician should be performed every 3-6 months depending on the severity of the disease. Vitamin D supplementation might be required due to deficiency from rigorous sun protection. Psychological advisory and support groups are very important for patients and their families. The management of patients with neurological abnormalities includes the use of hearing aid devices, with physical, occupational, and speech therapy [14]. Genetic counseling should be offered for families at risk. Antenatal diagnosis is possible in some countries by amniocentesis or chorionic villi sampling.

\section{Case Presentation}

We present the case of a 12-year-old Colombian male patient, son of first cousins, who was diagnosed with intrauterine growth restriction at 6 months prenatally and was born at term, with normal weight $(3000 \mathrm{Kg})$ and height $(49 \mathrm{~cm})$ for gestational age (40 weeks). Since the age of 3 months he started developing multiple skin lesions, initially in the face, which then extended to the whole body, mainly in sunexposed areas. The family history revealed similar recurrent skin cancers in 2 cousins on the maternal side of the family, who died at ages 8 and 12 years (Figure 2(a)). At the time of evaluation the patient had developed approximately 15 basal and squamous cell carcinomas in the face, ears, nose, eyes, and the extremities, which were surgically removed and no melanoma had been diagnosed. In addition to the dermatologic manifestations, the patient had been diagnosed with vitamin D deficiency due to excessive sun protection and also with detrusor hyperactivity plus detrusor-sphincter dyssynergia. Since infancy the patient also developed cognitive alterations, attention deficit/hyperactivity disorder, pes cavus, and progressive gait alterations. At 7 years he was diagnosed with bilateral cryptorchidism and hypogonadism by pediatric endocrinology. The physical exam revealed short stature (height: $133 \mathrm{~cm}$ ) (<2 SD), microcephaly (head circumference: $47.5 \mathrm{~cm})(<2 \mathrm{SD})$, low weight $(26 \mathrm{Kg})$, intellectual disability, altered speech, ataxic gait, and hyperreflexia, accompanying the skin findings: alopecia, freckle-like skin lesions, actinic keratoses sparing unexposed areas, and marked skin atrophy in eyelids and around the mouth (Figure 2(b)). Electromyography of the extremities and auditory evoked potentials were normal. Spine MRI revealed a normal spinal cord and cerebral MRI showed parenchymal volume loss, cerebellar atrophy, and white matter gliosis (Figure 2(c)). A commercial Xeroderma Pigmentosum Next Generation Sequencing panel including the genes DDB2, ERCC2, ERCC3, ERCC4, ERCC5, POLH, XP-A, and XPC revealed a homozygous germline sequence variant designated c.547A $>\mathrm{T}$ in the XPC gene, which was confirmed by Sanger sequencing. This variant is predicted to result in premature protein termination (p.Lys183*) and has not been previously reported in ClinVar and in The Human Gene Mutation Database, but is expected to be pathogenic. The karyotype was normal: 46XY with no structural or numerical chromosomal alterations. Genetic counseling, before and after genetic testing, was performed.

\section{Discussion}

We present a 12-year-old male with classical clinical manifestations of Xeroderma Pigmentosum and severe neurologic abnormalities (intellectual disability, ataxia, altered speech, and hyperreflexia), who carries a homozygous germline mutation in the XPC gene. Only 2 cases of XP with neurologic alterations have been described in the XPC complementation group; one was a 17-year-old female patient diagnosed with XPC and systemic lupus erythematosus, who presented with neurological and developmental abnormalities including microcephaly, intellectual disability, growth retardation, and primary amenorrhea [35]. The other was a 4-year-old patient from Korea with XPC who had hyperactivity, autistic features, and low levels of glycine [36].

Our patient's cerebral MRI revealed parenchymal volume loss, cerebellar atrophy, and white matter gliosis, which are characteristic of the De Sanctis-Cacchione syndrome (DSC). Even though XP with neurologic manifestations is still known sometimes as DSC, the latter is characterized by dwarfism and gonadal hypoplasia. Our patient shows classical features of DSC (intellectual disability, microcephaly, ataxia, hypogonadism, and dwarfism) with very early onset of skin lesions (3 months). Underlying molecular defects causing this disorder have been found in the ERCC6 (CS-B) gene, which encodes a DNA-binding protein that is important in transcription coupled excision repair and is also involved in Cockayne syndrome type B, as well as in XP-A and XP-D complementation groups $[37,38]$. This would be the first report of an XP-C mutation in De Sanctis-Cacchione syndrome.

A differential diagnosis in this patient is XP/CS complex, which presents as XP and the presence of Cockayne syndrome features. The patient has some CS signs (hyperreflexia, dwarfism, microcephaly, and hypogonadism) but does not have other XP/CS complex characteristics such as intracranial calcification, normal-pressure hydrocephalus, deafness, spasticity, and pigmentary degeneration of the retina $[15,30]$. Since the underlying molecular defect in XP/CS has been observed only in XP-B, XP-D, and XP-G, this would also be the first case of XP-C linked to XP/CS complex.

DSC and XP/CS complex have several overlapping clinical characteristics, making the distinction between both 


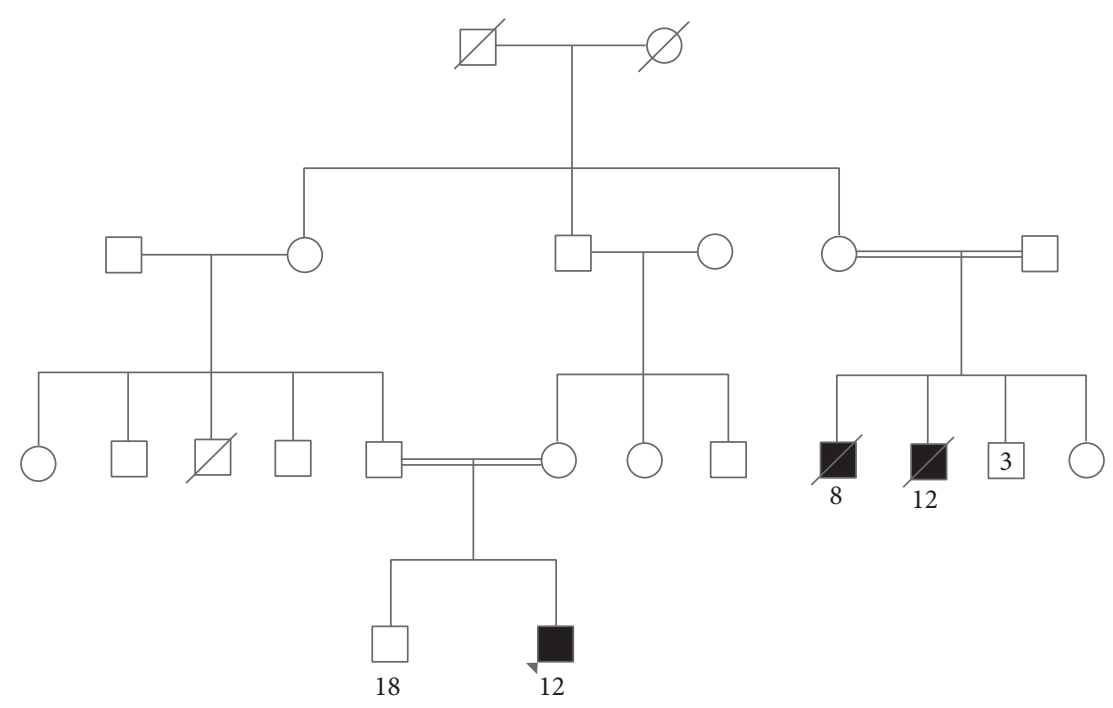

(a)

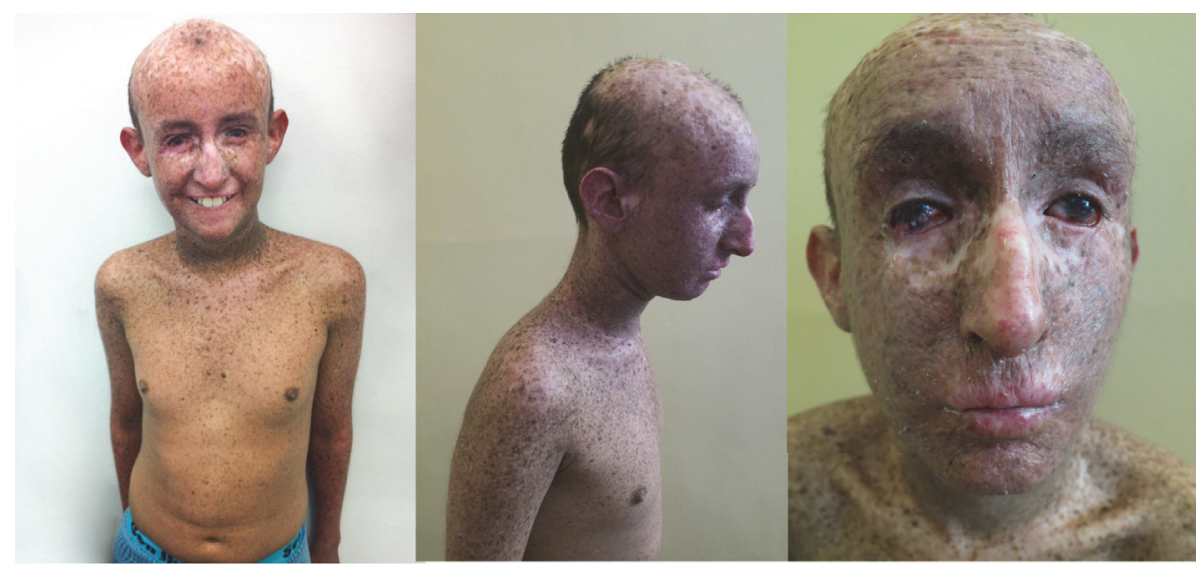

(b)

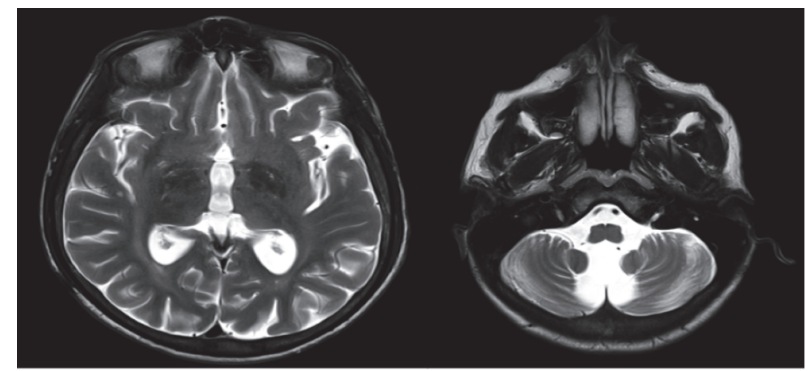

(c)

FIGURE 2: (a) Pedigree chart of the patient. The arrow indicates the index patient. Filled squares indicate affected individuals. (b) Photographs of the patient showing alopecia, freckle-like skin lesions, and actinic keratosis in sun-exposed areas. (c) Cerebral MRI showing parenchymal volume loss, cerebellar atrophy, and white matter gliosis.

syndromes difficult. Even the same mutation in the CS-B gene has been associated with both CS and DSC phenotypes, indicating that sometimes there is no clear genotype-phenotype correlation and that other genetic or environmental factors could determine the phenotype [37]. An intriguing feature observed in this patient is the severe alopecia, which is unusual in classical XP or in any of the XP-associated disorders (Figure 2(b)).
There are very few cases of De Sanctis-Cacchione reported in the literature and the complete spectrum of the De Sanctis-Cacchione syndrome has been recognized in very few individuals. Most of the reported patients have been diagnosed based only on clinical findings. In some cases in vitro functional assays to screen for abnormalities in DNA repair of UV-irradiated cells have been performed. Cell-fusion techniques followed by assessment of DNA repair are also 
used to determine the complementation groups. However, the exact underlying genetic defect has not been explored in most reported cases. With the advent of new sequencing technologies, where multigene panel testing has become cheaper, faster, and therefore more accessible in the clinical practice, it is now possible to do genetic testing for multiple genes simultaneously. Since many patients have overlapping features of different syndromes caused by nucleotide excision repair defects, it is now possible to establish better genotype-phenotype correlations in these genetic disorders, according to the affected gene and the specific mutation found within each gene. In our patient, full sequencing of the coding regions of the genes XP-A, XP-B/ERCC3, XPC, XP-D/ ERCC2, XPE/DDB2, XPF/ERCC4, XP-G/ERCC5, and XP variant/POLH and confirmation of variants by Sanger sequencing were performed, revealing a germline mutation in the XPC gene predicted to result in premature protein termination ( $\mathrm{p} . \mathrm{Lys} 183^{*}$ ). The majority of reported XPC mutations result in Premature Termination Codons (PTCs) $[36,39-42]$. There are few reports of missense type mutations in the XPC gene [41, 43-45].

Genetic counseling is very important when managing mendelian disorders, especially in populations where consanguinity is very common. The patient's parents were first cousins and he had two affected cousins who had died at young age, who were also born to consanguineous parents. Therefore, it is important that the patient's parents and other relatives understand the risk of passing on an autosomic recessive disorder to their children. Once a genetic defect is found in a family, the carrier status can be assessed in other family members.

\section{Conclusion}

Defects in the nucleotide excision repair (NER) system cause rare entities including Xeroderma Pigmentosum, De SanctisCacchione, Cockayne syndrome, and Trichothiodystrophy, which have higher incidence in areas with high levels of consanguinity. Since some of these syndromes have overlapping clinical features, it can be difficult in some instances to establish an accurate diagnosis. Molecular testing is necessary for a better classification of these disorders. The availability of faster and cheaper genetic testing methods will rapidly unveil the real genetic landscape underlying these disorders and a better genotype-phenotype correlation will allow us to manage better these patients. Direct mutation analysis can also be offered to at-risk individuals when a mutation is identified within a family. Although XP-mutation heterozygous carriers are clinically normal, there is active research regarding an increased cancer risk in these individuals.

\section{Consent}

Written informed consent was obtained from the patient's mother for publication of this clinical report and any accompanying images.

\section{Competing Interests}

The authors declare that they have no competing interests.

\section{References}

[1] J. E. Cleaver, "Defective repair replication of DNA in xeroderma pigmentosum," Nature, vol. 218, no. 5142, pp. 652-656, 1968.

[2] K. H. Kraemer, M. M. Lee, and J. Scotto, "Xeroderma pigmentosum: cutaneous, ocular, and neurologic abnormalities in 830 published cases," Archives of Dermatology, vol. 123, no. 2, pp. 241-250, 1987.

[3] I. Rapin, Y. Lindenbaum, D. W. Dickson, K. H. Kraemer, and J. H. Robbins, "Cockayne syndrome and xeroderma pigmentosum: DNA repair disorders with overlaps and paradoxes," Neurology, vol. 55, no. 10, pp. 1442-1449, 2000.

[4] J. H. Robbins, K. H. Kraemer, M. A. Lutzner, B. W. Festoff, and H. G. Coon, "Xeroderma pigmentosum: an inherited disease with sun sensitivity, multiple cutaneous neoplasms, and abnormal DNA repair," Annals of Internal Medicine, vol. 80, no. 2, pp. 221-248, 1974.

[5] W. J. Kleijer, V. Laugel, M. Berneburg et al., "Incidence of DNA repair deficiency disorders in western Europe: Xeroderma pigmentosum, Cockayne syndrome and trichothiodystrophy," DNA Repair, vol. 7, no. 5, pp. 744-750, 2008.

[6] Y. Hirai, Y. Kodama, S.-I. Moriwaki et al., "Heterozygous individuals bearing a founder mutation in the XPA DNA repair gene comprise nearly $1 \%$ of the Japanese population," Mutation Research, vol. 601, no. 1-2, pp. 171-178, 2006.

[7] M. Zghal, N. El-Fekih, B. Fazaa et al., "Xeroderma pigmentosum. Cutaneous, ocular, and neurologic abnormalities in 49 Tunisian cases," Tunisie Medicale, vol. 83, no. 12, pp. 760-763, 2005.

[8] K. H. Kraemer, M. M. Lee, A. D. Andrews, and W. C. Lambert, "The role of sunlight and DNA repair in melanoma and nonmelanoma skin cancer. The xeroderma pigmentosum paradigm," Archives of Dermatology, vol. 130, no. 8, pp. 1018-1021, 1994.

[9] S. G. Khan, K.-S. Oh, S. Emmert et al., "XPC initiation codon mutation in xeroderma pigmentosum patients with and without neurological symptoms," DNA Repair, vol. 8, no. 1, pp. 114-125, 2009.

[10] J. J. DiGiovanna and K. H. Kraemer, "Shining a light on xeroderma pigmentosum," Journal of Investigative Dermatology, vol. 132, no. 3, part 2, pp. 785-796, 2012.

[11] M. Ben Rekaya, O. Messaoud, F. Talmoudi et al., "High frequency of the V548A fs X572 XPC mutation in Tunisia: implication for molecular diagnosis," Journal of Human Genetics, vol. 54, no. 7, pp. 426-429, 2009.

[12] S.-I. Moriwaki and K. H. Kraemer, "Xeroderma pigmentosum-bridging a gap between clinic and laboratory," Photodermatology Photoimmunology and Photomedicine, vol. 17, no. 2, pp. 47-54, 2001.

[13] S. Moriwaki, "Human DNA repair disorders in dermatology: a historical perspective, current concepts and new insight," Journal of Dermatological Science, vol. 81, no. 2, pp. 77-84, 2016.

[14] A. R. Lehmann, D. McGibbon, and M. Stefanini, "Xeroderma pigmentosum," Orphanet Journal of Rare Diseases, vol. 6, article 70, 2011.

[15] T. M. Rünger, J. J. DiGiovanna, and H. Kenneth, "Hereditary disorders of genome instability and DNA repair," in Fitzpatrick's Dermatology in General Medicine, pp. 1-35, 8th edition, 2012.

[16] Y. Wang, D. Cortez, P. Yazdi, N. Neff, S. J. Elledge, and J. Qin, "BASC, a super complex of BRCA1-associated proteins involved in the recognition and repair of aberrant DNA structures," Genes and Development, vol. 14, no. 8, pp. 927-939, 2000. 
[17] J. Coulombe, D. Orbach, N. Soufir, and S. Hadj-Rabia, "Primary gingival squamous cell carcinoma in a xeroderma pigmentosum type C patient," Journal of the European Academy of Dermatology and Venereology, 2015.

[18] L.-C. Yang, Y.-P. Hsiao, C.-T. Lu et al., "Xeroderma pigmentosum complementation group C protein (XPC) expression in basal cell carcinoma," In Vivo, vol. 29, no. 1, pp. 35-38, 2015.

[19] J. J. DiGiovanna, N. Patronas, D. Katz, D. Abangan, and K. H. Kraemer, "Xeroderma pigmentosum: spinal cord astrocytoma with 9-year survival after radiation and isotretinoin therapy," Journal of Cutaneous Medicine and Surgery, vol. 2, no. 3, pp. 153$158,1998$.

[20] F. M. A. Butt, J. R. Moshi, S. Owibingire, and M. L. Chindia, "Xeroderma pigmentosum: a review and case series," Journal of Cranio-Maxillofacial Surgery, vol. 38, no. 7, pp. 534-537, 2010.

[21] S. Pintens, L. Pierret, K. Keymolen, J. Gutermuth, and L. De Raeve, "Xeroderma pigmentosum and leukaemia in two sisters," Journal of the European Academy of Dermatology and Venereology, vol. 30, no. 10, pp. e42-e43, 2016.

[22] H. L. Ramkumar, B. P. Brooks, X. Cao et al., "Ophthalmic manifestations and histopathology of xeroderma pigmentosum: two clinicopathological cases and a review of the literature," Survey of Ophthalmology, vol. 56, no. 4, pp. 348-361, 2011.

[23] A. D. Andrews, S. F. Barrett, and J. H. Robbins, "Xeroderma pigmentosum neurological abnormalities correlate with colonyforming ability after ultraviolet radiation," Proceedings of the National Academy of Sciences of the United States of America, vol. 75, no. 4, pp. 1984-1988, 1978.

[24] A. L. R. Caldas and M. M. Rodrigues, "De Sanctis-Cacchione syndrome in a female infant-case report," Anais Brasileiros de Dermatologia, vol. 88, no. 6, pp. 979-981, 2013.

[25] E. Rosón, I. García-Doval, C. De La Torre, C. Feal, and M. Cruces, "Síndrome de De Sanctis-Cacchione," Actas DermoSifiliográficas, vol. 96, no. 9, pp. 586-588, 2005.

[26] K. H. Kraemer, N. J. Patronas, R. Schiffmann, B. P. Brooks, D. Tamura, and J. J. DiGiovanna, "Xeroderma pigmentosum, trichothiodystrophy and Cockayne syndrome: a complex genotype-phenotype relationship," Neuroscience, vol. 145, no. 4, pp. 1388-1396, 2007.

[27] A. R. Lehmann, "DNA repair-deficient diseases, xeroderma pigmentosum, Cockayne syndrome and trichothiodystrophy," Biochimie, vol. 85, no. 11, pp. 1101-1111, 2003.

[28] Y. Lindenbaum, D. Dickson, P. Rosenbaum, K. Kraemer, J. Robbins, and I. Rapin, "Xeroderma pigmentosum/Cockayne syndrome complex: first neuropathological study and review of eight other cases," European Journal of Paediatric Neurology, vol. 5, no. 6, pp. 225-242, 2001.

[29] L. J. Niedernhofer, G. A. Garinis, A. Raams et al., "A new progeroid syndrome reveals that genotoxic stress suppresses the somatotroph axis," Nature, vol. 444, no. 7122, pp. 1038-1043, 2006.

[30] T. Nijsten, K. Lapière, and J. Lambert, "A patient with xeroderma pigmentosum treated with imiquimod $5 \%$ cream," Journal of the American Academy of Dermatology, vol. 52, no. 1, pp. 170-171, 2005.

[31] S. Leal-Khouri, G. J. Hruza, L. L. Hruza, and A. G. Martin, "Management of a young patient with xeroderma pigmentosum," Pediatric Dermatology, vol. 11, no. 1, pp. 72-75, 1994.

[32] J.-Q. Yang, X.-Y. Chen, M. Y. Engle, and J.-Y. Wang, "Multiple facial basal cell carcinomas in xeroderma pigmentosum treated with topical imiquimod 5\% cream," Dermatologic Therapy, vol. 28, no. 4, pp. 243-247, 2015.
[33] K. H. Kraemer, J. J. DiGiovanna, A. N. Moshell, R. E. Tarone, and G. L. Peck, "Prevention of skin cancer in xeroderma pigmentosum with the use of oral isotretinoin," The New England Journal of Medicine, vol. 318, no. 25, pp. 1633-1637, 1988.

[34] D. Yarosh, J. Klein, A. O'Connor, J. Hawk, E. Rafal, and P. Wolf, "Effect of topically applied T4 endonuclease V in liposomes on skin cancer in xeroderma pigmentosum: a randomised study. Xeroderma Pigmentosum Study Group," The Lancet, vol. 357, no. 9260, pp. 926-929, 2001.

[35] J. Hananian and J. E. Cleaver, "Xeroderma pigmentosum exhibiting neurological disorders and systemic lupus erythematosus," Clinical Genetics, vol. 17, no. 1, pp. 39-45, 1980.

[36] S. G. Khan, H. L. Levy, R. Legerski et al., "Xeroderma pigmentosum group $\mathrm{C}$ splice mutation associated with autism and hypoglycinemia," Journal of Investigative Dermatology, vol. 111, no. 5, pp. 791-796, 1998.

[37] S. Colella, T. Nardo, E. Botta, A. R. Lehmann, and M. Stefanini, "Identical mutations in the CSB gene associated with either Cockayne syndrome or the DeSanctis-Cacchione variant of xeroderma pigmentosum," Human Molecular Genetics, vol. 9, no. 8, pp. 1171-1175, 2000.

[38] T. Kanda, M. Oda, M. Yonezawa et al., "Peripheral neuropathy in xeroderma pigmentosum," Brain, vol. 113, no. 4, pp. 10251044, 1990.

[39] S. G. Khan, K.-S. Oh, T. Shahlavi et al., "Reduced XPC DNA repair gene mRNA levels in clinically normal parents of xeroderma pigmentosum patients," Carcinogenesis, vol. 27, no. 1, pp. 84-94, 2006.

[40] E. M. Gozukara, S. G. Khan, A. Metin et al., "A stop codon in xeroderma pigmentosum group $\mathrm{C}$ families in Turkey and Italy: molecular genetic evidence for a common ancestor," Journal of Investigative Dermatology, vol. 117, no. 2, pp. 197-204, 2001.

[41] F. Chavanne, B. C. Broughton, D. Pietra et al., "Mutations in the XPC gene in families with xeroderma pigmentosum and consequences at the cell, protein, and transcript levels," Cancer Research, vol. 60, no. 7, pp. 1974-1982, 2000.

[42] A. J. Ridley, J. Colley, D. Wynford-Thomas, and C. J. Jones, "Characterisation of novel mutations in Cockayne syndrome type A and xeroderma pigmentosum group C subjects," Journal of Human Genetics, vol. 50, no. 3, pp. 151-154, 2005.

[43] L. Li, E. S. Bales, C. A. Peterson, and R. J. Legerski, "Characterization of molecular defects in xeroderma pigmentosum group C," Nature Genetics, vol. 5, no. 4, pp. 413-417, 1993.

[44] G. Yasuda, R. Nishi, E. Watanabe et al., "In vivo destabilization and functional defects of the xeroderma pigmentosum $\mathrm{C}$ protein caused by a pathogenic missense mutation," Molecular and Cellular Biology, vol. 27, no. 19, pp. 6606-6614, 2007.

[45] M. Meneses, M. Chavez-Bourgeois, C. Badenas et al., "Atypical clinical presentation of xeroderma pigmentosum in a patient harboring a novel missense mutation in the XPC gene: the importance of clinical suspicion," Dermatology, vol. 231, pp. 217221, 2015. 


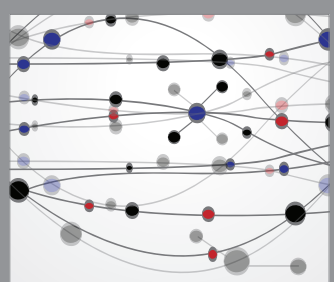

The Scientific World Journal
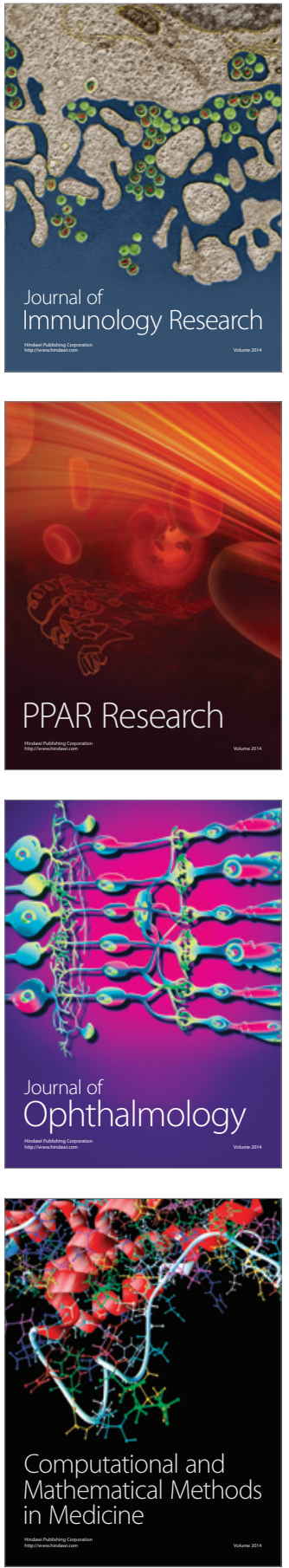

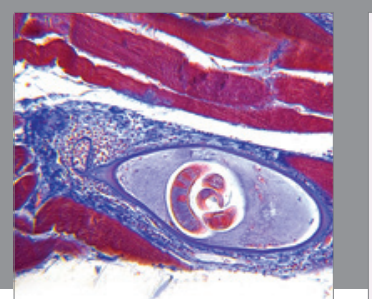

Gastroenterology Research and Practice
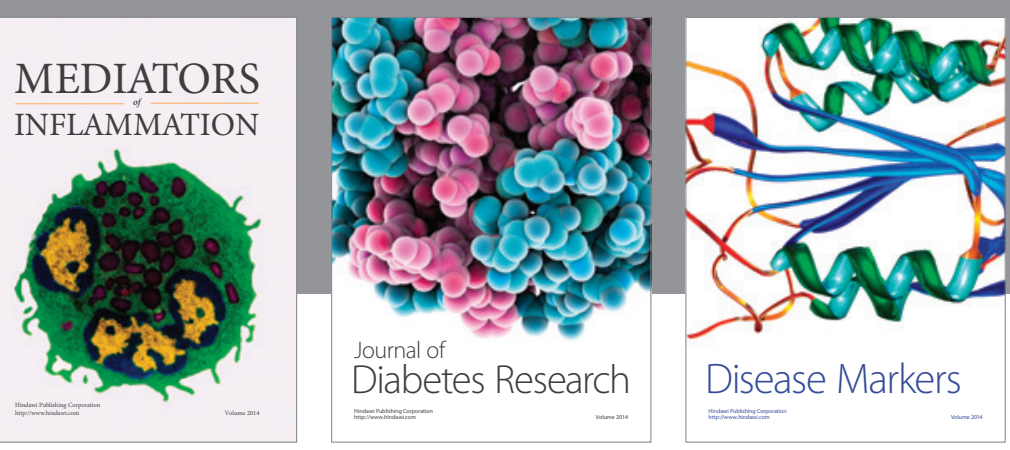

Disease Markers

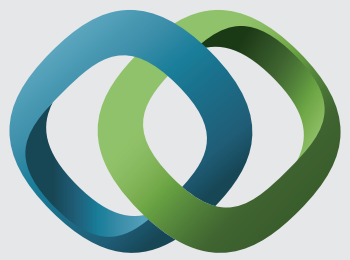

\section{Hindawi}

Submit your manuscripts at

https://www.hindawi.com
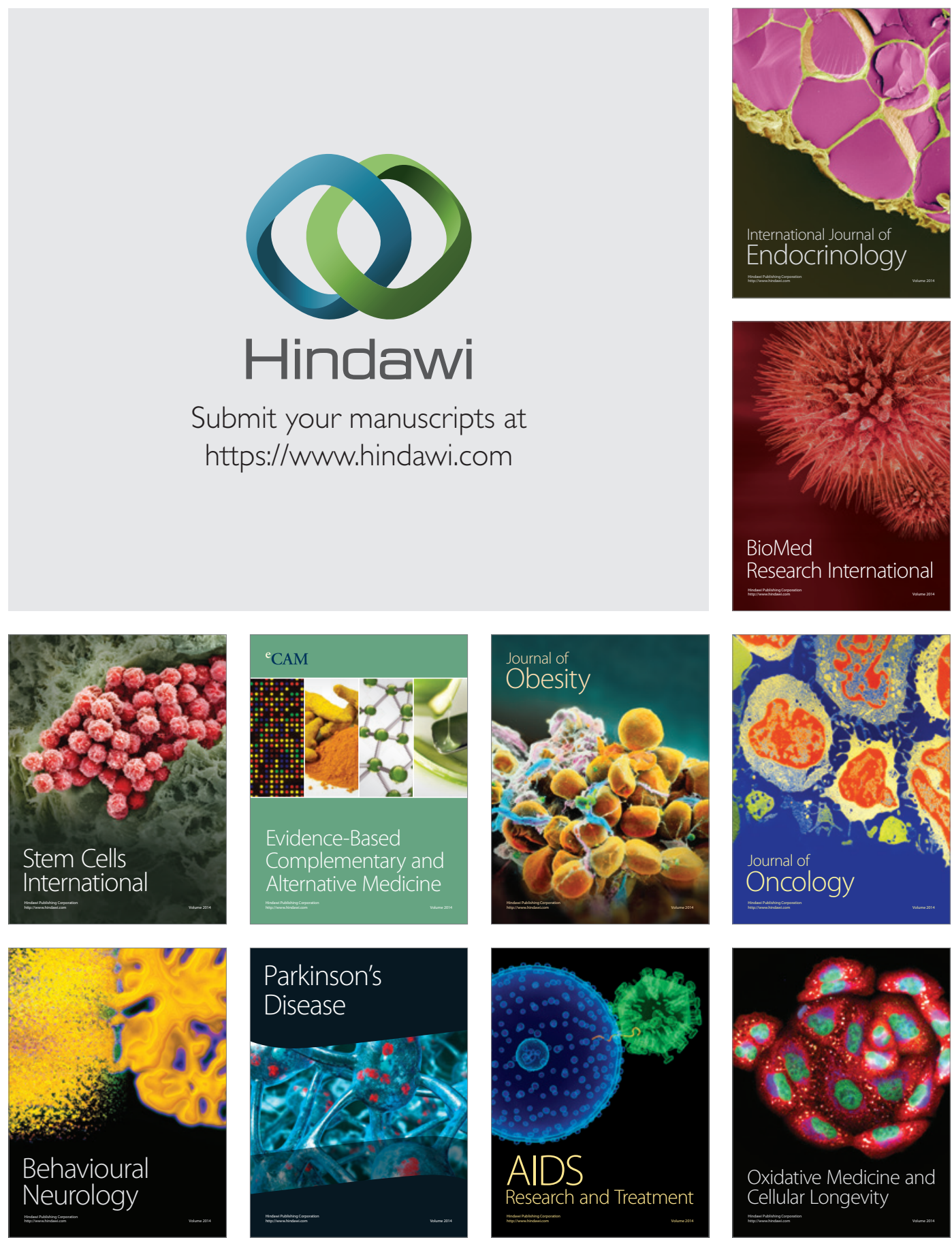